\title{
Outcomes of Pectoralis Major Myocutaneous Flap in the Reconstruction of Head and Neck
}

\author{
Shashidhar Kallappa ${ }^{1, *}$, Akshatha Shetty Mijar ${ }^{2}$ \\ ${ }^{1}$ Department of Surgical Oncology, Karnataka Institute of Medical Sciences, Hubli, India \\ ${ }^{2}$ Department of Otorhinolaryngology, Karnataka Institute of Medical Sciences, Hubli, India \\ Email address: \\ drshashi75@rediffmail.com (S. Kallappa), akshathashettym@gmail.com (A. S. Mijar) \\ ${ }^{*}$ Corresponding author
}

To cite this article:

Shashidhar Kallappa, Akshatha Shetty Mijar. Outcomes of Pectoralis Major Myocutaneous Flap in the Reconstruction of Head and Neck. International Journal of Clinical Oncology and Cancer Research. Vol. 5, No. 2, 2020, pp. 39-42. doi: 10.11648/j.ijcocr.20200502.15

Received: May 24, 2020; Accepted: June 10, 2020; Published: June 20, 2020

\begin{abstract}
Pectoralis major myocutaneous (PMMC) flap is versatile flap used for reconstruction of various head and neck defects created after excision of tumors. Due to the rapid advancement of reconstructive microsurgery, micro vascularised free flap transfer is becoming the main method of head and neck reconstruction. Presently PMMC flap reconstruction is used as an option for salvage surgery post free flap transfer failure and also in patients who are poor candidates for free flap transfer. However in developing countries like India where there are limited resources and the patient's presents in advanced stage of the disease PMMC flap is a viable option for reconstruction. Aim is to study the outcome of PMMC flap reconstruction in head and neck malignancy. A prospective analysis was done with 20 patients who underwent wide local excision with marginal or hemi mandibulectomy with PMMC flap reconstruction and neck dissection from January 2017 to January 2019 in tertiary care center. Follow up was done for every 2 weeks for first 2 months, then every month for a period of 6 months. Out of all the patients who underwent PMMC flap reconstruction, 2 patients developed partial flap necrosis, 1 had wound dehiscence and fistula and 1 patient had local recurrence. For remaining patients no complications were noted in the follow up period.
\end{abstract}

Keywords: Head and Neck Reconstruction, PMMC Flap, Complications of PMMC Flap

\section{Introduction}

Reconstruction of defects in the head and neck region caused due to surgical excision of the malignancy is a daunting task because it leads to both functional as well as cosmetic deficits, hence it has an impact on the day today life of the patient. Currently available options for reconstruction are pedicled flaps and free flaps.

Micro vascular free flap method is now considered to be the standard method in head and neck reconstruction. In developing countries like ours it cannot be used in every centers as it requires special techniques and equipments for microsurgery $[1,2]$ and also this method cannot be used effectively in cases with recurrence following reconstruction (salvage) or with poor systemic conditions, or following full dose radiotherapy or with arteriosclerosis or in elderly [3].

Pectoralis major myocutaneous (PMMC) flap was first described by Ariyan [4] since then it has been used for reconstruction of head and neck defects either after primary extirpation or surgical salvage after radiation failure and also considered as a workhorse for reconstruction in many head and neck surgeries. Advantages of this flap reconstruction will be its simple anatomy, location adjacent to head and neck region, can be elevated as vascular island flap, it has the shorter operative time, easy to execute and low donor site morbidity $[5,6]$.

\section{Materials and Method}

Current prospective study was conducted in the department of surgical oncology in Karnataka institute of medical sciences, Hubli from January 2017 to January 2019. Out of the 20 cases, 1 case was post hemiglossectomy with neck secondaries, 1 was carcinoma floor of mouth, 1 was carcinoma of gingivolabial sulcus, 2 were alveolar malignancy and rest were carcinoma of buccal mucosa.

Demographic data including age, sex, systemic 
morbidities, prior treatment, site of the tumour and any adjuvant treatment received were collected. Stage of the disease was evaluated using clinical and radiological examination. All the patients underwent wide local excision with marginal / hemimandibulectomy with PMMC flap reconstruction. Standard technique for harvesting PMMC flap was implemented. Success of flap reconstruction and complications were noted. Follow up was done for every 2 weeks for first 2 months and then monthly for a period of 6 months.

\section{Surgical Technique}

Surface markings of acromiothoracic artery outline taken. Skin island over the distal part of the muscle to facilitate suitable arc of rotation taken. Incision extended till the axilla and deepened to the level of muscle. Skin paddle was sutured to underling pectoralis muscle. During flap elevation, care was taken not to undercut the skin paddle but rather bevel it, so as to include as many myocutaneous perforators as possible. The dissection plane between pectoralis major and minor is obtained by dissecting the lateral border of pectoralis major muscle. Pectoralis major muscle was separated from minor. Pectoralis major muscle was divided lateral to the pedicle while keeping the pedicle in view, thereby freeing it from humerus. The flap was now passed into the neck through a subcutaneous tunnel created superficial to the clavicle. The tunnel was made wide enough to permit easy delivery of the flap without any compression. Flap was sutured using vicryl 3-0. Suction drains were placed in chest and neck and wound was closure done in layers. Figures 1 to 4 depict the surgical steps.

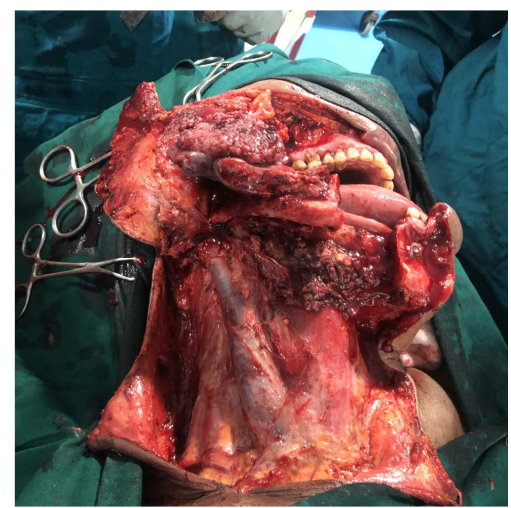

Figure 1. Surgical defect after hemimandibulectomy and neck dissection.

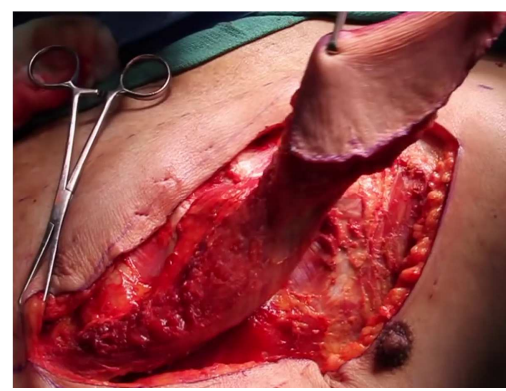

Figure 2. Flap dissection and rotation.

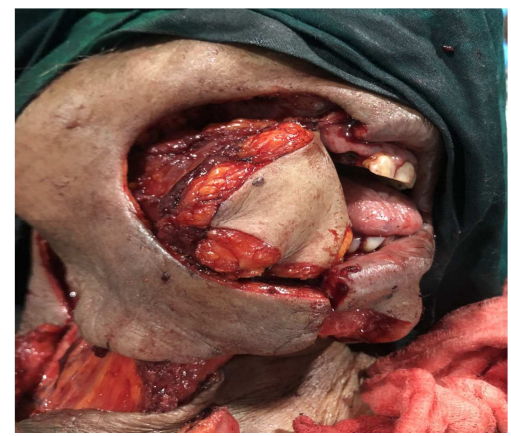

Figure 3. Flap inserted to the surgical defect.

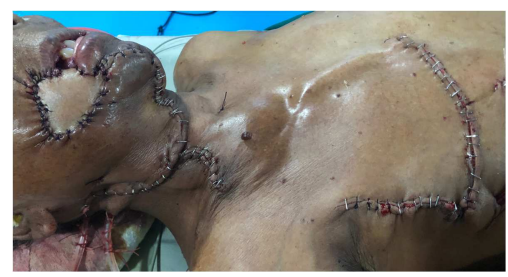

Figure 4. Immediate post operative picture of PMMC flap reconstruction.

\section{Observation and Results:}

During the study period of January 2017 to January 2019, total 20 patients underwent PMMC flap reconstruction out of which $16(80 \%)$ were males and $4(20 \%)$ females. Of the total 20 cases 1 was status post hemiglossectomy with recurrence, 1 was carcinoma of the floor of the mouth, 2 were alveolar malignancy rest were carcinoma buccal mucosa. Out of these 13 cases were stage III and 7 were stage IV a.

Carcinoma involving floor of mouth underwent marginal mandibulectomy and rest of the patients underwent hemimandibulectomy with PMMC flap reconstruction. Follow up was done every 2 weeks for 2 months, then monthly for a period of 6 months and various complications were assessed which included donor site infection, bleeding, wound dehiscence, total or partial flap necrosis, fistula and hematoma. Figure 5 shows postoperative follow up at $3^{\text {rd }}$ month.

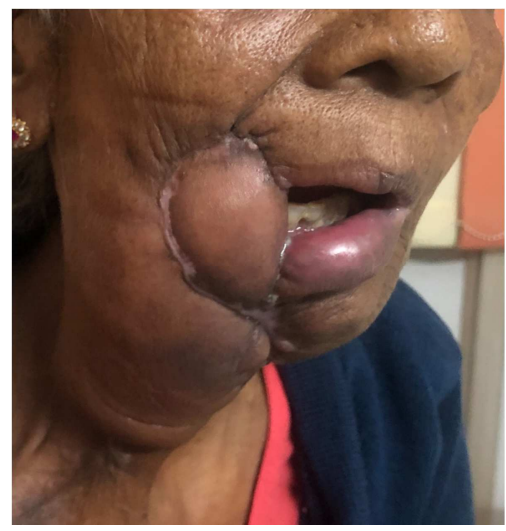

Figure 5. Post operative follow up of PMMC flap reconstruction.

Overall $20 \%$ (4) of the patients developed complications. Rest $80 \%$ of the patients had uneventful recovery without developing any complications. (Figure 6) 


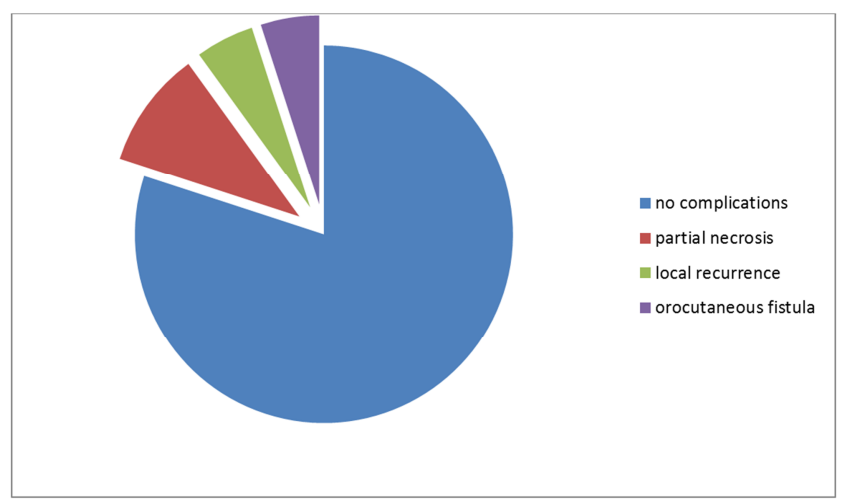

Figure 6. Percentage of complications in PMMC flaps reconstruction.

Out of the patients who developed complication, 2 patients had partial flap necrosis both were known diabetic and underwent surgical debridement and skin grafting as treatment. 1 patient had developed local recurrence after 1 year of surgery, was treated by wide local excision and nasolabial flap reconstruction shown in figure 7. 1 patient developed wound dehiscence was treated with systemic antibiotics.

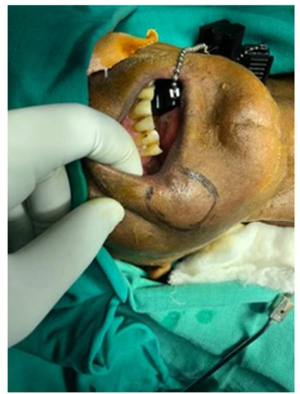

(a)

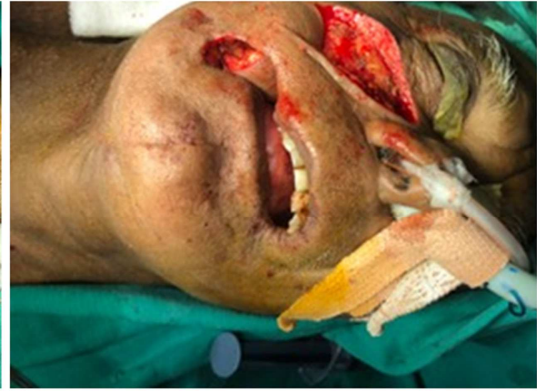

(b)
Figure 7. Patient with local recurrence (a) and was treated with wide local excision and naso labial flap reconstruction (b).

\section{Discussion}

PMMC flap was first described by Ariyan [4] post that it has widely used in head and reconstruction worldwide. Currently free flap reconstruction is the first choice for head and neck reconstruction, providing one stage restoration with lower morbidity and better cosmetic and functional results. However PMMC flap continues to be an important tool for head and neck surgeons in developing countries like India with high patient load, limited resources and patients generally presents in advanced stage of disease $[1,7]$.

PMMC flap can be used in wide range of defects in the head and neck region including neck, maxilla and temperoorbital area. Skin paddle can be extended as down as rectus abdominal sheath and the advantage of PMMC is that a very big skin paddle overlying whole of muscle can be elevated $[8,9]$. Study conducted by Kurse et al it was inferred that PMMC flaps are much suited for reconstruction of large defects $[10,11]$. In our study as well, all the patients belonged to advanced stage of the disease with large defects for reconstruction with complication rate of $20 \%$ we too concluded that it is appropriate flap for reconstruction of huge defects in head and cancers.

Recently microvascular free flaps are considered the gold standard method for reconstruction of major defects following head and neck cancer surgery [12]. In the era of microsurgical free flaps, pedicled flaps still hold their position for the reconstruction of oral cavity cancers [13]. Study conducted by Pancholi $\mathrm{M}$ et al have shown PMMC flap to be easy, done early and adds to the bulk of reconstructed tissue thereby maintaining the contour especially in full thickness cheek defects post hemimandibulectomy or maxillectomy where a radial forearm flap will leave a distinct hollow due to lack of bulk [14]. In our study all the patients belonged to advanced stages of the disease, requiring marginal /hemimandibulectomy hence resulting in larger cavities all were treated with PMMC flaps and have given good results.

Study conducted by Kruse et al [15] had 17 male and 3 females with mean age being 60 . In our study also there were 17 males and 3 females with mean age being 52 comparable with referred study.

Study conducted by Saito et al [16] among 12 patients amount of complications were $50 \%$, study conducted by Milenovic et al [17] had 33\% complications. In our study overall complications related to flap were found to be $20 \%$. Similar rates were seen by the study conducted by Kruse et al [15] with complication rate being $20 \%$ and Sagayaraj et al [18] showed $25 \%$ of complications.

Castelli et al [19] described in their study the effects of old age and systemic diseases on use of a PMMC flap related complications for reconstruction in head and neck surgery. They observed that the overall complications occurred more frequently in patients with underlying pathologies. It was found in their study that the use of PMMC flap in patients who suffer concomitantly with various known medical problems had increase in complication rates. Similar thing was evident in our study as well, patient with co morbid conditions developed more complications. In our study 2 patients $68 \mathrm{yr}$ and $65 \mathrm{yr}$ old both were known case of diabetic mellitus had partial necrosis of the flap. Both were treated by wide local excision and free skin grafting over muscle flap.

Another common complication of PMMC flap reconstruction is total or partial flap necrosis [20]. In our study partial flap necrosis was seen among 2 patients i.e. $10 \%$ and none of the patients developed total flap necrosis. Similar results were noted in study conducted by Bhanja A et al [21] with partial flap necrosis of $15 \%$, and Brusati et al [22] with partial necrosis of $9 \%$. There are other studies which has shown higher rate partial flap necrosis like the conducted by Nagral et al [23] who reports partial necrosis of $32 \%$ in 19 patients and Saito et al [16] noted partial flap loss in 4 patients when they performed PMMC flap reconstruction in 12 patients.

Study conducted by McLean et al [24] among 139 patient $3 \%$ developed fistula owing to wound dehiscence or partial loss of skin island. Similar results were found in our study, 1 patient $(5 \%)$ developed wound dehiscence and later fistula and was treated conservatively. Patient improved within 2 
weeks of treatment.

Local recurrence encountered in one of our patient within 1 year of surgery and was treated with wide local excision and nasolabial flap reconstruction.

\section{Conclusion}

PMMC flap can be considered as reliable technique for reconstruction of advanced stages of oral cavity malignancy with large defects. PMMC offers an easier, faster and reliable option with minimal complication rates and minimal donor site morbidity. Despite microvascular flaps being the preferred method in developing countries like ours which are resource constrained in terms of micro vascular reconstruction techniques PMMC remains an excellent reconstructive option in head and neck surgeries.

\section{References}

[1] Tripathi M, Parshad S, Karwasra R, Singh V. Pectoralis major myocutaneous flap in head and neck reconstruction: An experience in 100 consecutive cases. Natl J Maxillofac Surg. 2015.

[2] El-Marakby HH. The reliability of pectoralis major myocutaneous flap in head and neck reconstruction. J Egypt Natl Canc Inst. 2006.

[3] Kanno T, Nariai Y, Tatsumi H, Karino M, Yoshino A, Sekine J. A modified pectoralis major myocutaneous flap technique with improved vascular supply and an extended rotation arc for oral defects: A case report. Oncol Lett. 2015.

[4] Ariyan S. The pectoralis major myocutaneous flap: A versatile flap for reconstruction in the head and neck. Plast Reconstr Surg. 1979.

[5] Rikimaru H, Kiyokawa K, Inoue Y, Tai Y. Three-dimensional anatomical vascular distribution in the pectoralis major myocutaneous flap. Plast Reconstr Surg. 2005.

[6] Liu HL, Chan JYW, Wei WI. The changing role of pectoralis major flap in head and neck reconstruction. Eur Arch OtoRhino-Laryngology. 2010;

[7] Jena A, Patnayak R, Sharan R, Reddy SK, Manilal B, Rao LMC. Outcomes of pectoralis major myocutaneous flap in female patients for oral cavity defect reconstruction. J Oral Maxillofac Surg. 2014.

[8] Lekawale DH, Patil DB. Pectoralis Major Myocutaneous Flap for Oral Cavity Cancer Reconstruction - Our Experience with 30 Cases. Indian J Appl Res. 2011.

[9] Rahman QB, Karmakar R, Kumar S. Thoracoacromial Vessel Based Pectoralis Major Myocutaneous Flap in Oral and Maxillofacial Soft Tissue Defect Reconstruction. Anwer Khan Mod Med Coll J. 2012.
[10] Amin MM, Naseer U, Akhtar A, Awan AA. Pectoralis Major Myocutaneous Flap for Reconstruction of Major Neck Defects. Journal of Surgery Pakistan. 2014; 19 (2).

[11] Sathyanarayan GR, Suresh K P, Prabhu V. Pectoralis Major Myocutaneous (PMMC) Flap for Reconstruction of oro Facial Defect. JIADS. 2011; 2 (2): 76-8.

[12] Schusterman MA, Miller MJ, Reece GP, Kroll SS, Marchi M, Goepfert H. A single center's experience with 308 free flaps for repair of head and neck cancer defects. Plast Reconstr Surg. 1994; 93: 472-8.

[13] Pinto FR, Kanda JL. Delayed pharyngoesophageal reconstruction with combined local and regional flaps: A case report. Ear Nose Throat J. 2011; 90: E20-4.

[14] Pancholi M, Sharma S, Desai S, Agrawal D. Crossed pectoralis major myocutaneous flap for recurrent oral cavity cancers. Ann Maxillofac Surg. 2016.

[15] Kruse AL, Luebbers HT, Obwegeser JA, Bredell M, Grätz KW. Evaluation of the pectoralis major flap for reconstructive head and neck surgery. Head Neck Oncol. 2011.

[16] Saito A, Minakawa H, Saito N, Nagahashi T. Indications and outcomes for pedicled pectoralis major myocutaneous flaps at a primary microvascular head and neck reconstructive center. Mod Plast Surg 2012; 2: 103-7.

[17] Milenović A, Virag M, Uglešić V, Aljinović-Ratković N. The pectoralis major flap in head and neck reconstruction: First 500 patients. J Cranio-Maxillofacial Surg. 2006.

[18] Sagayaraj A, Deo RP, Azeem Mohiyuddin SM, Oommen Modayil G. Island Pectoralis Major Myocutaneous Flap: An Indian Perspective. Indian J Otolaryngol Head Neck Surg. 2012.

[19] Castelli ML, Pecorari G, Succo G, Bena A, Andreis M, Sartoris A. Pectoralis major myocutaneous flap: a0 nalysis of complications in difficult patients. Eur Arch Otorhinolaryngol 2001; 258: 542-5.

[20] Patel K, Lyu DJH, Kademani D. Pectoralis major myocutaneous flap. Oral and Maxillofacial Surgery Clinics of North America. 2014.

[21] Bhanja A, D'Souza DSJ, Roy C, Poddar RN. Reliability of the pectoralis major myocutaneous flap in reconstructive oral cancer surgery in developing countries: Our experience. Med J Armed Forces India. 2016.

[22] Brusati R, Collini M, Bozzetti A, Chiapasco M, Galioto S. The pectoralis major myocutaneous flap. Experience in 100 consecutive cases. J Craniomaxillofac Surg 1988; 16: 35-9.

[23] Nagral S, Sankhe M, Patel CV. Experience with the pectoralis major myocutaneous flap for head and neck reconstruction in a general surgical unit. J Postgrad Med 1992; 38: 119-23.

[24] McLean JN, Carlson GW, Losken A. The pectoralis major myocutaneous flap revisited: A reliable technique for head and neck reconstruction. Ann Plast Surg. 2010; 64: 570-3. 